\title{
DONAS DE CASA: Classes DIFERENTES, EXPERIÊNCIAS DESIGUAIS
}

\author{
Luciana da Silva Santos* \\ Gláucia Ribeiro Starling Diniz**
}

\section{Resumo}

Este artigo apresenta resultados de uma pesquisa de mestrado. Esta buscou mostrar a condição de mulheres de diferentes classes sociais que, nos dias atuais, se mantêm como donas de casa, indo na contramão do "novo" modelo feminino. Foram entrevistadas três mulheres donas de casa de diferentes classes sociais: baixa, média e alta. A análise do discurso das entrevistas gerou três categorias: (a) significado do trabalho doméstico, (b) condição feminina e vida privada e (c) satisfação e (des)valorização do trabalho doméstico. Concluiu-se que as desigualdades socioeconômicas entre as participantes contribuíram para as diferentes significaçóes dadas ao trabalho doméstico e às experiências decorrentes. As falas das mulheres revelaram o peso da realidade socioeconômica na significação e no valor atribuído às suas funçóes e à condição feminina.

Palavras-chave: dona de casa; classe social; gênero.

\section{Abstract}

HOUSEWIVES: DIFFERENT CLASSES, UNEQUAL EXPERIENCES

This article presents results of a master degree research regarding the condition of women of different social classes who stay home as housewives, going apparently against the "new" female model. We interviewed three housewives from the following social classes: low, medium and high. Discourse analysis of the interviews appointed three categories: (a) the meaning of domestic labor; (b) feminine condition and private life; and (c) satisfaction and (or versus) (de)value

* Mestre e doutoranda do Programa de Pós-Graduação em Psicologia Clínica e Cultura pela Universidade de Brasília.

** Coordenadora do Programa de Pós-graduação em Psicologia Clínica e Cultura da Universidade de Brasília. 
(devaluation) of housework. The discourse of the women revealed the weight of the economic reality in the meaning and value they attributed to their functions and status as women.

Keywords: housewife; social class; gender.

\section{INTRODUÇÃO}

A saída de mulheres do âmbito doméstico para o trabalho remunerado fora do lar é vista como um grande acontecimento. Este, por sua vez, provocou, entre outras consequências, novos modelos e arranjos de família. A valorização dessas mulheres que saem do espaço privado para desbravar um lugar no espaço público, genuinamente masculino, provavelmente inaugura uma nova condição do feminino. Em outra seara, se encontram mulheres que não romperam com a mítica de "rainha-do-lar", do lugar tradicional feminino e que continuam a desempenhar, exclusivamente, a função doméstica - em espaço privado e sem remuneração. A condição feminina de mulheres que se mantêm aparentemente na contramão da história merece atenção.

O termo dona de casa surgiu durante a industrialização. Fazer essa afirmação é possível quando se olha para o contexto histórico, político e econômico em que ele nasce. Sua origem está ligada ao modelo econômico capitalista que, ao despontar, trouxe consigo uma ideologia que dividiu a sociedade ocidental em duas esferas distintas: um espaço particular, restrito, privado que foi "disponibilizado" às mulheres e o outro, coletivo, irrestrito, público, destinado aos homens (Bruschini, 2007; Hirata, 2001; Saffioti, 1976, 1979).

A instituição da família nuclear - idealizada pela burguesia nascente - atribuiu papéis específicos de gênero na sociedade. A mulher foi denegada de papel social na vida pública, ficando sua atuação restrita à esfera privada. Na separação dessas esferas, as condiçóes biológicas das mulheres foram usadas como argumento para lhes atribuir o lugar no mundo doméstico. A natureza feminina e as especificidades do ciclo vital que incluem a menstruação, gravidez e amamentação passaram a justificar o seu confinamento ao espaço privado - visto como o seu lugar natural, de direito e dever em função de sua realidade biológica. $\mathrm{O}$ cuidado dos filhos passou a ser também atribuição exclusiva das mulheres (Bruschini, 2007; Hirata, 2004; Saffioti, 1987).

Esse processo de naturalização de características biológicas funcionou como um marcador social, tendo como resultado a divisão sexual do trabalho (Hirata, 2001; Hirata \& Kergoat, 2007). Diferenças converteram-se gradativamente em desigualdades, uma vez que mulheres passaram a ser excluídas ou impedidas de

Psic. Clin., Rio De JANEIRo, vol.23, N.2, P.I37 - I49, $201 \mathrm{I}$ 
exercer funções nos âmbitos acadêmico, político e econômico. As atividades sociais produtivas tornaram-se domínio do masculino, enquanto a função social reprodutiva foi delegada ao feminino.

Mulheres passaram a ser, sistematicamente, preparadas para serem mães e esposas notáveis: elas foram convocadas a se dedicarem ao papel de "rainhas-dolar". Ocorre, dessa forma, um movimento de idealização e valorização do exercício desse papel. Inseridas nesse modelo, mulheres foram aparentemente reconhecidas por seu desempenho no espaço privado. Uma família "perfeita" era produto do trabalho de uma esposa exemplar. Tal idealização dificultou ou desqualificou a inserção de mulheres em outros espaços sociais (Biasoli-Alves, 2000; Diniz, 1999, 2004; Moraes, 1997).

Os movimentos sociais que ocorreram ao longo do século XX, em especial o movimento feminista, colocaram em debate essa rígida divisão de trabalho entre homens e mulheres. Estudos, reflexóes e açóes políticas, com foco na condição feminina, passaram a situar a mulher em diferentes lugares. Consequentemente, transformaram o seu papel na política, na economia, na religiāo, na família, no trabalho, dentre outras instituições (Araújo \& Scalon, 2005; Biasoli-Alves, 2000; Bruschini, 2007; Diniz, 2004; Jablonski, 2007).

Este contexto que permitiu a saída de mulheres das classes média e alta do âmbito doméstico para o exercício do trabalho remunerado, fora do lar, produziu, entre outras consequências: novos modelos de ser mulher, de ser homem, além de questionar a divisão social do trabalho (Perlin \& Diniz, 2005). Respeitadas as diferenças de classes e de realidades sociais, a mulher - que outrora se dedicava exclusivamente aos cuidados da casa, dos(as) filhos(as) e do marido - assume outra função: a de profissional. Ao assumir esse papel, a mulher não só modifica o espaço público como abre a possibilidade de construir novos papéis sociais femininos.

Esses papéis femininos inauguram um processo complexo de modificação cultural, marcado por contradiçóes. Pesquisas realizadas no Brasil (Araújo \& Scalon, 2005; Jablonski, 2007, Perlin \& Diniz, 2005; Rocha-Coutinho, 2004) mostram que a domesticidade, como lugar do feminino, ainda constitui a grande barreira para a inserção da mulher na vida social. Mesmo desenvolvendo atividades fora do lar, as mulheres continuam sendo as principais responsáveis pelas atividades no espaço privado (Bruschini, 2007; Bruschini \& Lombardi, 2000; Hirata, 2004; Madalozzo, Martins, \& Shiratori, 2010). Esse fato, além de reforçar a divisão tradicional de papéis entre os sexos, gera um ideal de mulher difícil, senão impossível, de ser alcançado. Ou seja, além de ser capaz de buscar independência financeira, valorização profissional, satisfação conjugal e sexual, essa nova mulher precisa ser competente para administrar o lar, educar os(as) filhos(as) e manter uma boa rede social. 
É nesse contexto social de mudanças, de coexistência de novos e velhos modelos (Rocha-Coutinho, 2004), que se faz necessário compreender a experiência de mulheres que optam por permanecer em casa, exercendo papéis tradicionais. Questiona-se de que maneira esse movimento intenso de migração de mulheres do domínio privado para o público gera processos de marginalização em parcelas da própria categoria feminina. Qual a importância dada às mulheres que não exercem atividades no domínio público? Que status têm as mulheres de distintas classes sociais que vivem unicamente para o cuidado da casa, do esposo e dos(as) filhos(as)? Quais os valores que a sociedade, formada por homens e mulheres, tem apontado para as mulheres que não possuem uma profissão remunerada e/ou trabalho fora do lar?

Esses questionamentos justificam o interesse em desenvolver pesquisa de mestrado (Santos, 2008) sobre a experiência de mulheres que permanecem como donas de casa, ou seja, que realizam o trabalho doméstico não-pago. A intenção deste estudo foi conhecer, de forma geral e exploratória, dimensóes da experiência de mulheres donas de casa de diferentes classes sociais, visto que os processos históricos, econômicos e políticos produzem distintas realidades para mulheres pertencentes às diferentes estratificaçóes sociais.

\section{Método}

\section{AMOSTRA E PROCEDIMENTOS}

Fundamentando-se em estudos de gênero e em uma produção científica feminista, optou-se pelo uso do método qualitativo para nortear os passos desta pesquisa por este conter elementos condizentes com as práticas feministas (Narvaz \& Koller, 2006; Neves \& Nogueira, 2005). Realizamos um estudo de casos múltiplos, com três mulheres que eram exclusivamente donas de casa e não possuíam qualquer fonte de renda individual. Uma mulher de cada classe social - baixa, média e alta - foi entrevistada. A classificação social usou como parâmetro a renda familiar associada a outros marcadores sociais, como, por exemplo: lugar e condição de moradia, bens mencionados, trabalho/cargo do marido etc.

As participantes, moradoras de cidades do Distrito Federal, foram: Maria das Dores - baixa-renda - 53 anos, negra, católica praticante, ensino fundamental incompleto, casada há 38 anos, mãe de 4 filhas e 1 filho (todos adultos); Maria Amélia - classe média - 33 anos, branca, católica não praticante, ensino médio completo, casada há 15 anos, mãe de filha adolescente; e Maria dos Prazeres - classe 
alta - 63 anos, branca, católica praticante, ensino médio completo, casada há 30 anos, mãe de 3 filhos adultos. Todos os nomes são fictícios.

Realizamos entrevistas semiestruturadas que incluíam perguntas abertas e um roteiro pré-estabelecido. Elas foram gravadas com permissão das entrevistadas, após assinatura do Termo de Consentimento Livre e Esclarecido. As entrevistas foram transcritas na íntegra, sem alteraçóes ou qualquer tipo de correçóes gramaticais. Escolhemos o método de Análise do Discurso para fundamentar a análise dos dados coletados com base nos trabalhos de Brandáo (2004) e Rocha-Coutinho (2006). O projeto que fundamentou esta pesquisa foi submetido e aprovado pelo Comitê de Ética em Pesquisa da Faculdade de Ciências da Saúde da Universidade de Brasília.

\section{CONSTATAÇÕES E REFLEXÕES: A (IN)VISIBILIDADE DA MULHER DONA DE CASA}

A intenção desse estudo foi compreender as consonâncias e dissonâncias existentes entre os discursos de cada participante e problematizar os resultados com base na literatura levantada. A partir das entrevistas, do discurso das participantes, foram construídas categorias para análise. Através desse processo obtivemos três categorias: (A) significado do trabalho doméstico; (B) condiçâa feminina e vida privada; e (C) satisfação e (des)valorização do trabalho doméstico. Estas categorias serão apresentadas e problematizadas a seguir.

A- Significado do trabalho doméstico

O significado atribuído às atividades realizadas no cotidiano doméstico variou conforme a realidade socioeconômica de cada participante. Esse fato fica explícito nos depoimentos aqui apresentados.

Maria dos Prazeres, classe alta, ao falar de sua vida como dona de casa, relatou que suas funçóes são: saber delegar os afazeres domésticos, administrar a casa, cuidar da saúde de todos e das finanças. Segundo ela, as atividades que merecem destaque são: ser o sustento emocional da casa e exercer o importantíssimo papel de ser máe, de cuidar e educar, de prover referências para uma nova geraçáo. Ela afirma: "[...] é a administração da casa, a economia da casa, e a saúde da família, é a educação da família, né?”.

Maria Amélia, classe média, também ressaltou a importância de seu trabalho como administradora de sua casa e controladora dos gastos familiares. Ela define: "Dona de casa pra mim significa ser gerente da minha casa [...]". Além dessa função, a participante destacou a importância de seu papel como colaboradora para 
o bem-estar profissional do marido ao proporcionar-lhe um ambiente familiar harmonioso.

Maria das Dores, de baixo poder aquisitivo, enfatizou o fato de sua vida ser marcada por uma sobrecarga de trabalho. Ela contou que se desdobra entre o cuidado com filhos(as) e netos(as) e as obrigações com os afazeres domésticos, principalmente com as atividades domésticas mais pesadas - lavar e passar roupa, limpar a casa, cozinhar.

Os relatos apontam diferentes funçóes e vivências do papel de dona de casa. Os trabalhos de Duran (1983), Madalozzo et al. (2010) e Poeschl (2000) corroboram os resultados desta pesquisa. Os autores destacam que as mulheres de classes privilegiadas possuem uma função mais administrativa, de coordenar as atividades domésticas, uma vez que têm posses suficientes para delegar os trabalhos domésticos às instituiçóes ou pessoas que fornecem tais serviços. Já a dona de casa de família de baixa renda, além de realizar sozinha todos os trabalhos domésticos (pois não tem como e nem a quem repassar tais trabalhos), não possui condição de descanso e acesso a lazer.

Uma questão importante trazida tanto por Maria dos Prazeres quanto por Maria Amélia foi o autorreconhecimento da importância de seu trabalho como forma de trazer economia à família. Segundo elas, tal economia se dá pelo fato de elas realizarem atividades que, se fossem pagas a alguém ou a alguma instituição, trariam ônus reais à família. Elas afirmaram que teriam que receber um bom salário para poder recompensar as suas ausências do lar, se optassem por trabalhar fora.

Esse argumento das participantes de classe média e alta encontra eco no trabalho de Melo, Considera e Sabbato (2007). De acordo com os(as) autores(as), esse é um discurso revelador de, pelo menos, dois aspectos importantíssimos do trabalho da dona de casa em relação à economia. O primeiro mostra que se os afazeres domésticos (só os executados pelas mulheres, que correspondem a 82\%) fossem contabilizados como serviços não-mercantis produzidos e consumidos pela família, em 2006 o PIB brasileiro teria sido de 2.535,8 bilhões de reais -213 bilhóes a mais que o anunciado pelo IBGE (Instituto Brasileiro de Geografia e Estatística). O segundo aspecto, decorrente do primeiro, é o fato de esses dados servirem como retrato da exclusão voluntária do mercado de trabalho, por parte de algumas mulheres, em função dos baixos salários praticados no Brasil. Nesse caso, os custos de exercer uma atividade remunerada e não dedicar-se às atividades domésticas não compensariam tal escolha.

Além disso, os resultados desta pesquisa também apontaram que a realidade econômica interfere na forma como as mulheres significam os seus trabalhos. As experiências de vida das pessoas são constituídas, também, pelas diferenças

Psic. Clin., Rio De JANEIRo, vol.23, N.2, P.I37 - I49, $201 \mathrm{I}$ 
socioeconômicas que contribuíram para a produção de diferentes estilos de vida e formas de significá-los. No caso das mulheres participantes desta pesquisa, é visto que, ainda que elas exerçam o mesmo papel de donas de casa, a forma de executar e os instrumentos ou recursos utilizados no exercício da atividade são diferenciados em função da realidade socioeconômica de cada uma.

\section{B- Condição feminina e vida privada}

O papel de dona de casa é originário do desdobramento da condição feminina. Foi possível identificar, através dos discursos das participantes, a presença de herança cultural de gênero. Esta estabelece rígidas divisóes de papéis entre masculino e feminino, além de colocar a mulher no espaço privado e o homem, no público.

No discurso de Maria Amélia, fica claro que ser mulher é ser dona de casa, é cumprir os papéis das brincadeiras infantis de casinha, de boneca. Com isso, realiza um conjunto de atribuiçóes, miticamente construído como de pertencimento ao feminino. Sendo fiel às suas palavras temos: "É aquela coisa de realizá o sonho de quando se é criança que brinca de casinha".

Maria dos Prazeres fala que a existência de mulheres exclusivamente donas de casa é uma condição indispensável à sobrevivência da humanidade, ou seja, contribui para que a sociedade não fique sem eixo, sem a base que sustenta as famílias. Essa dona de casa de classe alta é categórica: "Olha, eu acho assim, que se não houverem, se não existisse, se não continuar existindo (gesticulando com a mão direita, rodopiando o dedo indicador) esse tipo de dona de casa, muito filho, muita filha vai ficar meio perdido porque não tem o eixo que é a dona de casa. $A$ mãe, é o eixo da casa!".

Nesses discursos percebe-se a transmissão cultural pela qual as participantes passaram. Maria Amélia afirmou que se espelhou na mãe dona de casa. Disse também que sua família de origem não projetou seu futuro profissional, mas sim o seu lugar como máe e cuidadora do lar. Maria dos Prazeres explicitou a ideia de que as geraçóes passadas preparavam a mulher para a vida doméstica e demarcavam o lugar social feminino. Maria das Dores também deixou subentendido que, em geraçóes anteriores, a educaçáo e a profissionalizaçáo das mulheres não eram objetivos da sociedade.

Cabe ressaltar, entretanto, que vários fatores têm provocado transformações na condição feminina na contemporaneidade. Houve um tempo em que permanecer no espaço privado - lugar da mulher dona de casa - significava estar completamente reclusa. Hoje essa experiência comporta dimensóes diferenciadas de isolamento e inserção social. 
Maria das Dores mencionou que, quando estava estressada, deixava as crianças sozinhas e viajava. E, ainda: "[...] quando termino aqui meus serviço, vou sempre na casa de um e de outro [...]. Meus irmáo mora por aqui, tudim pertim de mim". Maria Amélia fez referência às saídas ao shopping com amigas, entre outras possibilidades de socialização: "[...] aí vou pro mercado já vê o que eu vou fazer pro almoço, uma conversa com a vizinha não pode faltá (risos)". E Maria dos Prazeres comentou que, além de viagens, realiza, semanalmente, um trabalho voluntário em uma instituição de caridade. As três mulheres - em graus diferentes - relataram situaçóes que nos permitem refletir que, provavelmente, ser dona de casa e dedicar-se integralmente à vida familiar não tenha mais a mesma configuração de reclusão ou abnegação que historicamente possuiu.

Nas entrevistas encontramos que o homem, pelo menos nesse tipo de configuração conjugal e familiar, continua a ocupar um lugar privilegiado, em conformidade com os trabalhos de Bruschini (2007), Duran (1983), Farias (1983), Hirata \& Kergoat (2007), Madalozzo et al. (2010), Moraes (1997) e Poeschl (2000). Compreendemos que, por mais que as duas mulheres com melhores condiçóes financeiras tenham dito que são donas do dinheiro dos maridos, que administram as contas ou compras e que possuem liberdade financeira - por terem cartóes de crédito ou conta conjunta que facilitam o poder de compra -, nos seus discursos ficou tácito que o poder do homem, esposo e provedor da família ainda é soberano: "[...] eu é que coordeno, eu é que faço, meu marido me delega isso aî" (Maria dos Prazeres). "Eu sirvo a eles, eu retribuo, já que ele trabalha, ele paga tudo dentro de casa” (Maria Amélia).

C- Satisfação e (des)valorização do trabalho doméstico

Ao falar do trabalho realizado no espaço doméstico e sem remuneração, as participantes ressaltaram pontos que as satisfazem e recompensam, assim como outros que provocam desvalorizaçáo. Dentre as satisfaçóes, a maternidade foi, indiscutivelmente, o principal ponto de convergência. No presente estudo, ainda que apresentando variaçôes quanto às circunstâncias ou às necessidades econômicas, as três donas de casa afirmaram como principal vantagem de ficar em casa o fato de poder cuidar dos(as) filhos(as) pessoalmente.

Maria das Dores afirmou que essa opção foi feita pela necessidade de estar perto dos(as) filhos(as) para protegê-los(as) da vulnerabilidade social e das condiçôes de riscos aos quais estavam e permanecem submetidos(as) por residirem em uma periferia perigosa. Ela foi enfática ao dizer que esse é o único motivo de felicidade por ter sido dona de casa a vida toda: "[...] por isso eu gostei de ser dona de casa, mas só por causa disso. Porque tomei conta deles".

Psic. Clin., Rio De JANEIRo, vol.23, N.2, P.I37 - I49, $201 \mathrm{I}$ 
Maria Amélia ressaltou que é satisfatório e valorativo ouvir a filha agradecer por ela "[...] não ser como as outras mães e poder ficar em casa". E, ainda, que "[...] não saberia atribuir a outra pessoa a função de cuidar de minha filha única $e$ adolescente, sem falar nos gastos que teria com cursinhos para ocupar o tempo e a mente dela".

Maria dos Prazeres afirmou que a presença dos filhos foi determinante para ela náo voltar ao mercado de trabalho, lugar que ocupou brevemente antes de se casar. Ela disse que não queria que os filhos tivessem prejuízos em função de sua ausência. Além disso, afirmou que os gastos com instituiçóes e pessoas para cuidar deles seriam superiores aos ganhos financeiros conquistados com o seu salário. Este posicionamento condiz com dados de alguns trabalhos publicados no Brasil (Bruschini, 1995; Moraes, 1997; Rocha-Coutinho, 2004, 2005; Saffioti, 1987). Estas autoras ressaltam que a maternidade continua sendo o principal motivo para as mulheres náo entrarem ou não permanecerem no espaço público, devido, principalmente, à culpa que sentem por sacrificar a criação dos filhos.

A unanimidade quanto à satisfação em ser dona de casa encerrou-se com a maternidade. $\mathrm{O}$ reconhecimento ou valorização de seus trabalhos foi outra dimensão que revelou, mais uma vez, que a mulher de classe social alta e a de classe média compartilham experiência distinta da participante de classe menos favorecida. As mais abastadas afirmaram receber reconhecimento de seus familiares: "[...] porque eu acho que eles (referindo-se aos filhos e ao marido) dão valor. Eles sabem, eles tão felizes porque eu vivi exclusivamente pra eles [...]" (Maria dos Prazeres). "[...] porque ele (o marido) vê e admira né?". Ou ainda, "a minha filha agradece por eu ficar em casa" (Maria Amélia).

Por outro lado, Maria das Dores em nenhum momento fez qualquer menção à valorização de seu papel na família. Ao contrário, o único comentário a respeito foi: "ninguém nunca falou nada".

Nas entrevistas, nos discursos de Maria dos Prazeres e Maria Amélia também ficaram explícitos os seus (re)sentimentos em relação à valorização de sua opção de ser dona de casa frente ao meio social: "Eu acho, tenho às vezes até convicção, que as pessoas me veem como uma não faz nada da vida” E ainda: “[...] mas eu te confesso que perante a sociedade, quando meu marido me apresenta para alguém que eu ainda não conheço, eu sinto sim que existe comigo uma dificuldade de dizer que eu sou dona de casa porque não é, não é, não tem reconhecimento, não é admirável" (Maria Amélia). "[...] a gente gostaria às vezes de ser mais valorizada, né? [...] ah, porque há muito preconceito, há muita coisa assim com a dona de casa, é como se ela náo fizesse nada [...]. É como se ela fosse assim.... uma pessoa que não faz droga nenhuma, né? Não, não, não!” (Maria dos Prazeres). 
As posiçóes socioeconômicas de Maria Amélia e Maria dos Prazeres parecem deixá-las em desconforto quanto ao reconhecimento ou desqualificação de suas funçóes. Ainda que elas se valorizem ou que sejam reconhecidas pela família, há preocupações com a desvalorização social.

As participantes desta pesquisa atribuem esse desconhecimento - ou desvalorização - de seu trabalho ao fato de a atividade da dona de casa ser vista como um trabalho improdutivo. Bruschini (2006) levanta a tese do trabalho das donas de casa vir a ser colocado como um trabalho "não-remunerado" e não como uma “inatividade econômica”. Em defesa dessa posição, ela analisa estudos desde os anos 1970 que tentam dar visibilidade ao trabalho doméstico e outros que usam o tempo para mensurar as atividades de produção ou de reprodução realizadas na sociedade. Ela chega à conclusão de que a quantidade de horas envolvidas nos afazeres domésticos, geralmente realizados por mulheres, constitui sim um trabalho, só que não-remunerado.

No mesmo sentido, Hirata e Kergoat (2007), Lavinas e Nicoll (2005), assim como Saffioti $(1976,1987)$, apontam que o trabalho realizado no âmbito doméstico não é valorizado por ser secularmente atribuído ao papel feminino, papel esse que ocultaria os serviços e a trabalhadora. No mais, ele também não é reconhecido por não representar uma contribuição monetária para o orçamento familiar. Entretanto, nas palavras das próprias donas de casa entrevistadas (Maria dos Prazeres e Maria Amélia), assim como na literatura (Bruschini, 2006; Duran, 1983; Melo et al., 2007), a economia gerada pela realização dos trabalhos domésticos reverte-se em ganhos para a família e para a sociedade. Chama atenção, portanto, o fato de esse ganho, de essa contribuiçáo econômica permanecer ignorada ou menosprezada.

\section{REFLEXóEs}

A análise dos discursos de três mulheres donas de casa, de diferentes estratificaçóes sociais, revelou o peso da realidade socioeconômica na significação e no valor atribuído às suas funções e à sua condição feminina. A experiência de ser mulher e dona de casa divergiu imensamente em funçáo da classe social de pertença. Esse dado reitera a importância de articular gênero com categorias como raça, classe, nível educacional, faixa etária, acesso a bens e serviços, dentre outras, para dar conta da complexidade e da multiplicidade de experiências de mulheres.

A visão pessoal a respeito do seu "universo" como dona de casa, a importância dada aos seus papéis e às suas responsabilidades no âmbito doméstico e social foi marcada, portanto, por um nível de esclarecimento e dilema diferenciado pelo 
recorte econômico e pelo nível educacional das mulheres entrevistadas. A autovalorização, autoestima ou a compreensão crítica de sua experiência como dona de casa eleva-se à medida que a renda familiar das mulheres também é aumentada. Tal fato pode ser explicado pelo acesso à cultura e às vivências que as condiçóes econômicas favoráveis possibilitam.

Esta pesquisa realizada com mulheres donas de casa também mostrou dimensóes novas do espaço privado, ao mesmo tempo que deixa evidente a presença de papéis e lugares tradicionais da categoria feminina. As participantes revelaram adesão a uma identidade tradicional de gênero, apresentando discursos que atrelam o homem ao espaço público - como provedor financeiro da família - e a mulher à responsabilidade pela família e pelo cuidado do lar e dos filhos.

Dentro desses papéis tradicionais da mulher, o mais profundo e unanimemente colocado foi a maternidade. Certamente, esse foi o motivo que as levou - de forma mais concreta - a voltarem ou permanecerem no espaço doméstico. Cabe ressaltar que essa experiência comum que aproximou o relato das mulheres fica minimizada frente ao abismo socioeconômico que as separa.

Esse trabalho promoveu reflexôes a respeito de dimensôes da experiência de três mulheres donas de casa e buscou contribuir para a construção de conhecimento científico sobre dimensôes da condição feminina, a partir de uma perspectiva de gênero. Esperamos que ele estimule investigaçóes sobre o tema - mulheres dona de casa - e abra portas para um diálogo com outros trabalhos que venham a tratar da interação entre gênero, divisão sexual do trabalho, raça, classe social, educação. Ao apontar dilemas em torno da (des)valorização e da (in)visibilidade da função de dona de casa, chama atenção para diferentes modalidades de participação econômica e social de mulheres e amplia o debate sobre a construçáo de novos papéis para homens e mulheres no casamento, na família e na sociedade.

\section{REFERÊNCIAS}

Araújo, C., \& Scalon, C. (2005). Gênero, família e trabalho no Brasil. Rio de Janeiro: Editora FGV.

Biasoli-Alves, Z. M. M. (2000). Continuidades e rupturas no papel da mulher brasileira no século XX. Psicologia Teoria e Pesquisa, 16(3), 233-239.

Brandão, H. (2004) Introdução à análise do discurso (7a ed.). Campinas, SP: Editora Unicamp.

Bruschini, C. (1995). Maternidade e trabalho feminino: sinalizando tendências. Reflexão sobre gênero e fecundidade no Brasil. Disponível em: da Family Health International: $<$ www.fhi.org $>$. 
Bruschini, C. (2006). Trabalho doméstico: inatividade econômica ou trabalho não remunerado? Revista Brasileira de Estudos da População, 23(2), 331-353.

Bruschini, C. (2007). Trabalho e gênero no Brasil nos últimos dez anos. Cadernos de Pesquisa, 37(132), 537-572.

Bruschini, C., \& Lombardi, M. (2000). A bipolaridade do trabalho feminino no Brasil contemporâneo. Cadernos de Pesquisa, 110, 67-104.

Diniz, G. (1999). Condição feminina - fator de risco para a saúde mental? In: Paz, M., \& Tamayo, A. (Orgs.). Escola, saúde e trabalho: estudos psicológicos (pp. 181-197). Brasília: Editora Universidade de Brasília.

Diniz, G. (2004). Mulher, trabalho e saúde mental. In: Codo, W. (Org.). O trabalho enlouquece? Um encontro entre a clinica e o trabalho (pp. 138-195). Petrópolis: Vozes.

Duran, M. (1983). A dona-de-casa: crítica politica da economia doméstica. (Coleção Tendências, v. 5). Rio de Janeiro: Ediçóes Graal.

Farias, Z. (1983). Domesticidade: “cativeiro" feminino? Rio de Janeiro: Achiamé/CMB.

Hirata, H. (2001). Globalização e divisão sexual do trabalho. Cadernos Pagu, 18(2), 139156.

Hirata, H. (2004). Trabalho doméstico: uma servidão voluntária? In: Godinho, T. \& Silveira, M. Coleção Cadernos da Coordenadoria Especial da Mulher-PMSP, no. 8.

Hirata, H., \& Kergoat, D. (2007). Novas configuraçôes da divisão sexual do trabalho. Cadernos de Pesquisa, 37(132), 595-609.

Jablonski, B. (2007). O cotidiano do casamento contemporâneo: a difícil e conflitiva divisão de tarefas e responsabilidades entre homens e mulheres. In: Féres-Carneiro, T. (Org.). Família e casal: saúde, trabalho e modos de vinculação (pp. 203-228). São Paulo: Casa do Psicólogo.

Lavinas, L., \& Nicoll, M. (2005). Direito previdenciário para donas-de-casa versus universalidade da proteção social do Brasil. Revista Proposta, Fase, 103/104, 01-41.

Madalozzo, R., Martins, S., \& Shiratori, L. (2010). Participação no mercado de trabalho e no mercado doméstico: homens e mulheres têm condiçóes iguais? Estudos Feministas, 18(2), 547- 566.

Melo, H., Considera, C., \& Sabbato, A. (2007). Os afazeres domésticos contam. Economia e sociedade, 16(3), 435-454.

Moraes, C. (1997). Dona-de-casa. A profissão invisivel. Rio de Janeiro: Objetiva.

Narvaz, M., \& Koller, S. (2006). Metodologias feministas e estudos de gênero: articulando pesquisa, clínica e política. Psicologia em Estudo, Maringá, 11(3), 647-654.

Neves, S., \& Nogueira, C. (2005). Metodologias feministas: a reflexividade ao serviço da investigação nas ciências sociais. Psicologia: Reflexão e Crítica, 18(3), 408-412.

Perlin, G., \& Diniz, G. (2005). Casais que trabalham e são felizes: mito ou realidade? Psicologia Clínica, Rio de Janeiro, 17(2), 15-29.

Psic. Clin., Rio De JANEIRo, vol.23, N.2, P.137 - I49, $201 \mathrm{I}$ 
Poeschl, G. (2000). Trabalho doméstico e poder familiar: práticas, normas e ideais. Análise Social, XXXV(156), 695-719.

Rocha-Coutinho, M. (2004). Novas opçôes, antigos dilemas: mulher, família, carreira e relacionamento no Brasil. Temas em Psicologia da SBP, 12(1), 2-17.

Rocha-Coutinho, M. (2005). Variações sobre um antigo tema: a maternidade para mulheres com uma carreira profissional bem-sucedida. In: Féres-Carneiro, T. (Org.). Família e casal: efeitos da contemporaneidade (pp. 122-137). Rio de Janeiro: Editora PUC-Rio.

Rocha-Coutinho, M. (2006). A narrativa oral, a análise de discurso e os estudos de gênero. Estudos de Psicologia, 11(1), 65-69.

Saffioti, H. (1976). A mulher na sociedade de classes: mito e realidade. (Coleção Sociedade Brasileira, v. 4). Petrópolis: Vozes.

Saffioti, H. (1979). Emprego doméstico e capitalismo. Rio de Janeiro: Avenir Editora Limitada.

Saffioti, H. (1987). O poder do macho. (5a ed.). Sáo Paulo: Moderna.

Santos, L. (2008). Profissão: do-lar. A (des) valorização do trabalho doméstico como desdobramento da (in)visibilidade do feminino. (Dissertação de mestrado). Curso de Pós-Graduação em Psicologia Clínica e Cultura Universidade de Brasília, Brasília, DF.

Recebido em 23 de fevereiro de 2011 Aceito para publicação em 28 de setembro de 2011 